\title{
Titularización de flujos futuros como financiamiento de los gobiernos autónomos descentralizados
}

\author{
Securing future flows as financing of \\ decentralized autonomous governments
}

Francisco Xavier Jácome Marín, Mgtr. (Autor corresponsal)

Docente titular UEES

\author{
Ab. Tanya Mishell Guillen Triana \\ Abogada de los Tribunales y Juzgados de la República del Ecuador \\ Artículo Original (Revisión) \\ RFJ, No. 4, 2018, pp. 335-354, ISSN 2588-0837
}

RESUMEN: el presente trabajo investigativo demuestra que la titularización de flujos futuros es una herramienta financiera idónea que se encuentra vinculada de manera directa con el mercado de valores en su segmento bursátil, regulada por el segundo libro del Código Orgánico Monetario y Financiero, Ley de Mercado de Valores; la cual puede ser utilizada por los Gobiernos Autónomos Descentralizados como fuente de financiamiento para la obtención de recursos al tiempo presente, y de esta manera cumplir con la realización de sus competencias exclusivas, las mismas que se encuentran determinadas por la Constitución de la República del Ecuador y el Código Orgánico de Organización Territorial. No obstante, la titularización a pesar de ser una herramienta que ofrece ventajas tanto para el originador como el inversionista, se puede denotar que la aplicación es escasa por parte de los Gobiernos Autónomos Descentralizados, lo que conlleva a determinar que existe falta de conocimiento sobre la utilidad que ofrece esta herramienta; para lo cual se propone que exista una mayor promoción y estudio por par parte de los GAD's sobre esta alternativa de financiamiento.

PALABRAS CLAVE: titularización de flujos futuros, gobiernos autónomos descentralizados, administración pública, autonomía financiera, descentralización

ABSTRACT: the present research shows us that the securitization of future flows is a suitable financial tool, which is directly link to the 
securities market, regulated by the second book of the Código Orgánico Monetario y Financiero, Ley de Mercado de Valores. This financial tool can be used by the Decentralized Autonomous Governments as a source of finance to obtain resources at present time, and achieve the realization of their exclusives competences, which are determined by the Constitution of the Republic of Ecuador and the Código Orgánico de Organización Territorial. However, the securitization, although it is a tool that offers advantages to the originator and the investor, it is evident the scarce application from of the Decentralized Autonomous Governments witch implies that there is a lack of knowledge about the benefits offered by this tool; for which it is propose for there be more promotion and study by the Decentralized Autonomous Governments on this alternative of finance.

KEY WORDS: securitization of future flow receivable, decentralized autonomous governments, public administration, financial autonomy, decentralization.

\section{INTRODUCCIÓN}

El término titularización es un vocablo que surge de la traducción de la palabra securitization, que a su vez se deriva del anglicismo securities; este fenómeno se originó en los Estados Unidos en los años treinta, creándose un organismo denominado Federal National Mortgages Association, con la finalidad de generar liquidez en el mercado habitacional, mediante el otorgamiento de préstamos hipotecarios, los cuales se financiaban a través de la emisión de títulos debidamente respaldados por la hipoteca. (Temiño Aguirre, 2007, pág. 29).

En el área iberoamericana el desarrollo de la titularización obedece la regulación del país en el que se desarrolla y la económica de la misma (Solbes Mira, 2007). En Ecuador se encuentra regulada por la Ley de Mercado de Valores, convirtiéndose en una opción atractiva para la obtención de recursos en el segmento bursátil, por parte de quienes buscan financiarse, y de esta manera desarrollar actividades por parte del sector privado o público.

El artículo 139 de la Ley de Mercado de Valores establece que podrán ser originadores del proceso de titularización personas jurídicas de derecho público, lo que implica que los Gobiernos Autónomos Descentralizados están habilitados para hacer uso de esta herramienta, y de esta 
manera alcanzar a obtener recursos para financiar la ejecución de sus competencias exclusivas, subsanando el déficit de recursos económicos y por consecuencia satisfaciendo las necesidades de los ciudadanos.

Siendo así, el objeto del presente trabajo investigativo se centrará en explicar que es una titularización con flujos futuros, el proceso que debe seguir un Gobierno Autónomo Descentralizado para utilizar esta herramienta financiera, y además se establecerá las ventajas e importancia que trae consigo esta herramienta financiera.

\section{LOS GOBIERNOS AUTÓNOMOS DESCENTRALIZADOS}

Con la entrada en vigencia de la Constitución de la República del Ecuador, la ciudadanía ecuatoriana optó por un Estado constitucional de derechos, justicia, social, soberano, democrático, independiente, unitario, intercultural, plurinacional y laico, pues así lo establece la Carta Magna en su artículo 1, el cual se caracteriza por la vinculación entre los órganos de la administración pública y los derechos constitucionales, la administración es garante de estos últimos.

La Norma Suprema (2008) en el artículo 227, define a la administración pública como un servicio a la colectividad. De esta manera, Jorge Zavala Egas agrega que es aquella que se encuentra integrada por sujetos del sector público, atribuidos de potestad estatal para desempeñar una función administrativa y prestar servicios públicos con el objeto de alcanzar el fin público (Lecciones de Derecho Administrativo, 2011, pág. 167).

Por consiguiente, la administración pública en aras de satisfacer necesidades de la colectividad, se ejerce mediante personas jurídicas o a través de los órganos que forman el sector público, este último según Andrea Martínez Dama es un conjunto de órganos que sirven para la ejecución de los cometidos estatales, satisfaciendo necesidades a través de la prestación de servicios públicos (La Necesaria Innovación en la Administración Pública, 2013, pág. 169).

Los Gobiernos Autónomos Descentralizados forman parte del sector público, y se caracterizan por ser una especie de autoridad o entidad (Derecho Constitucional del Ecuador, 2013, pág. 293), que gozan de autonomía política, administrativa y financiera. Se consideran gobiernos autónomos, las juntas parroquiales, rurales, los concejos municipales, metropolitanos, cencejos provinciales y regionales. 
Ahora bien, para una mejor comprensión sobre qué es un gobierno autónomo descentralizado, es imprescindible definir el término descentralización, según Agustín Gordillo, la misma implica que cierta competencia se ha atribuido a un nuevo ente, separado de la administración central, dotado de personalidad jurídica propia, y constituido por órganos propios que expresan la voluntad de ese ente. La descentralización stricto sensu se la conoce también como "descentralización autárquica," que supone la creación de entes separados de la administración central dotados de capacidad de actuar y administrarse así mismo (Tratado de Derecho Administrativo, 2013, pág. 371).

Los Gobiernos Autónomos Descentralizados, son personas jurídicas de derecho público que gozan de autonomía, y que en función de su ordenamiento jurídico deben ejecutar ciertas competencias exclusivas con la finalidad de satisfacer necesidades de los administrados. Al referirnos al término de autonomía, debe entenderse como el poder que tienen ciertos individuos o entes colectivos para crear un ordenamiento propio en el marco de otro superior (Estudio sobre el Poder Judicial, 1989); además se considera como potestad de autoorganización y autogobierno para la gestión de los propios intereses (Cayetano Núñez Rivero \& García Aranda, 2013, pág. 409).

La Autonomía de los GADs es de índole política, administrativa y financiera, el artículo 5, inciso segundo del Código Orgánico de Organización Territorial establece que la autonomía política se refiere al impulso de procesos de desarrollo considerando aspectos históricos, culturales y características innatas del territorio, la cual se expresa mediante las facultades normativas y ejecutivas, capacidad de emitir políticas públicas, elección directa y mediante el ejercicio de participación ciudadana. La autonomía administrativa de conformidad con el artículo 5, inciso tercero de la norma precitada, es el ejercer la organización y gestión de los talentos humanos (servidores públicos) y de los recursos materiales para llevar a cabo sus competencias.

Finalmente, la autonomía financiera alude a las fuentes de financiamiento y a la autogestión que tienen los gobiernos autónomos descentralizados para producir ingresos propios, independientes de lo que por ley percibe del presupuesto general del estado. La autogestión de los GADs ha incrementado el cumplimiento de sus competencias, según Ramón Eduardo Burneo los gobiernos autónomos descentralizados más eficientes en cuanto autogestión son los municipales y provinciales (Derecho Constitucional del Ecuador, 2013, pág. 293). 
Los GADs para el cumplimiento de sus competencias, necesitan de recursos financieros. En este punto surge la interrogante de qué forma los obtiene, es así que la normativa ecuatoriana ha instaurado diversas opciones que facilitan la generación de recursos propios o de autofinanciamiento, además de reglamentar las asignaciones ordinarias que se realizan del gobierno central a favor del gobierno local (Buendía, 2011).

De esta manera, los GADs de conformidad con el artículo 171 del COOTAD, obtienen sus recursos financieros a través de: (1) la participación en el presupuesto general del Estado; (2) de los ingresos propios de la gestión, siendo estos los que provienen de los impuestos, tasas y contribuciones especiales o de mejoras; (3) de las transferencias del gobierno central por la participación en las rentas de la explotación de los recursos no renovables; (4) de ingresos provenientes de financiamiento, el cual se obtiene mediante el endeudamiento público o la colación de títulos y valores.

De esta manera, al ser la colocación de valores una de las diferentes alternativas para la obtención de recursos financieros, será necesario cuestionar la forma en la que debe ejecutarse, para lo cual es necesario que el GAD participe en el mercado de valores como sujeto, ya que es el único sitio donde se pueden negociar valores. En el siguiente apartado se explicará qué es y como está conformado el Mercado de Valores, además de qué forma se colocan los valores.

\section{MERCADO DE VALORES}

El Mercado de Valores es el lugar en donde se genera la oferta y demanda de valores, este último es su objeto principal, para la emisión, colocación y negociación (Varón Palomino \& Abella Abondano, 2017, pág. 221). Para Andrade Ubidia, es el sitio donde se canalizan los recursos financieros hacía las actividades, a través de la negociación de los valores en los segmentos bursátil y extrabursátil (Los Títulos Valores en el Derecho Ecuatoriano, 2006)

Además, Víctor Cevallos Vásquez considera que la existencia del mercado de valores nacional facilita que los emisores de valores conviertan sus tenencias en efectivos y para aquellos que tienen efectivo compren los valores. (Manual de Derecho Mercantil, 2013, pág. 508). 
Para Fernando Martínez los valores tienen como característica, el ser de contenido patrimonial, lo que conlleva a que sea negociable en el sentido de ser capaces de contratación masiva e impersonal, no solo en un mercado primario sino también en un secundario (Manual de Derecho Mercantil, 2014, pág. 301). Al ser negociables los valores suponen contar con un instrumento que permita captar recursos del público, siendo representada a través de documento o instrumento idóneo de contenido patrimonial y la disposición del derecho que incorpora (Valencia Copete \& Garcés, 2008, pág. 731).

Según el artículo 2 de la Ley de Mercado de Valores, se considera valor al derecho de contenido económico y negociable, la normativa ecuatoriana establece los tipos de valores, tales como las acciones, obligaciones, bonos, cuotas de fondos de inversión colectivos, valores de contenido crediticio, de participación y mixto que provengan de procesos de titularización, entre otros.

Los valores se negocian en el mercado primario o secundario de valores, la primera debe interpretarse como aquel lugar en el que se distribuyen de manera originaria los valores. Desde un punto de vista económico conlleva al ahorro hacia la inversión, como alternativa al mercado de crédito, y desde una posición jurídica, a la adquisición primaria de los valores negociables (Muñoz Machado, 2010, pág. 123). Así mismo, el mercado secundario es la venta de aquellos valores adquiridos en un mercado primario por quien los compro originariamente (Cidoncha Martín, 2009, pág. 124). Es decir son negocios que se realizan de manera posterior a la primera colocación

Una vez explicado de manera general qué es el Mercado de Valores en el Ecuador, es necesario explicar de manera sucinta quienes conforman el mercado de valores. Se considera conformado por la bolsa de valores, el catastro público de valores y por las casas de valores. La bolsa de valores son sociedades anónimas creadas con el fin de proporcionar infraestructura y servicios eficaces en la negociación de valores (Ramirez Solano , 2001). El catastro público del mercado de valores es el registro de información pública, referente a los emisores y valores a emitirse, y es esencial la inscripción, para la participación en el mercado bursátil. Las casas de valores son las únicas habilitadas para actuar en calidad de intermediaria en la compra y venta de valores (Andrade V, 2003, pág. 156). 
En relación con quienes participan en el mercado de valores, se destacan dos grandes grupos, emisores e inversionistas, el primer grupo se caracteriza por ser entidades o unidades económicas que requieren financiamiento; quienes a su vez se clasifican en i) emisores públicos, que comprenden el gobierno central, seccional, instituciones y organismos gubernamentales y empresas pública, ii) emisores privados iii) patrimonios autónomos, fondos colectivos, entre otras figuras. Los inversionistas son aquellas personas naturales o jurídicas de Derecho público o privado, cuya capacidad económica les permite invertir en valores emitidos por los emisores, y para la debida adquisición deben acudir a los intermediarios (Ayala Brito \& Becerril Sánchez , 2011, pág. 45).

De lo mencionado en párrafos anteriores podemos destacar que los Gobiernos Autónomos Descentralizados al formar parte del sector público, pueden ser participantes del mercado de valores dentro del segmento bursátil. Para lo cual se deberá considerar la regulación de la participación del sector público en calidad de emisor de valores, la misma que se encuentra establecida en el Tomo IX, Libro II de la Codificación de Resoluciones Monetarias, Financieras de Valores y Seguros. Es esencial la inscripción en el catastro público del mercado de valores de las entidades del sector público para su participación, esta se caracteriza por ser automática, debe ser notificada a la Superintendencia de Compañías con su debida justificación legal para emitir valores.

\section{TITULARIZACIÓN}

De conformidad con el artículo 138 de la Ley de Mercado de Valores, la titularización "es el proceso mediante el cual se emiten valores susceptibles de ser colocados y negociados libremente en el mercado bursátil, emitidos con cargo a un patrimonio autónomo", Lovato Saltos (2013) califica la definición dada por la legislación ecuatoriana como imprecisa, debido a la falta de determinación en relación con los elementos esenciales, lo que implica la utilización de doctrina para resaltar las características de este proceso.

Para Mario Kenny la titularización es un procedimiento mediante el cual determinados activos ilíquidos, se transforman en activos financieros líquidos, para su negociación en el mercado de capitales, en forma de valores, es decir es un proceso a través del cual se emiten valores susceptibles de colocación y negociación en el segmento bursátil (Titulización y Fideicomiso Financiero, 2007, pág. 1). 
Juan Manuel Preire, la define como un proceso nuevo en referencia a las alternativas preexistentes, tales como la colocación de acciones y la emisión de obligaciones, debido a que esta modalidad conlleva a financiarse a través de la enajenación de derechos de cobro, los cuales se encuentran incorporados en valores. La titularización agrupa activos o derechos de cobro, los cuales se transfieren a un patrimonio autónomo, adquiriéndose de esta manera fondos mediante la emisión de valores, y estos últimos ofreciendo a los inversionistas un derecho de participación o crédito sobre tales activos (El Contrato de Fideicomiso Financiero, 2012, págs. 136-137).

De las definiciones aportadas por doctrinarios y legislación ecuatoriana, se destacan ciertas características que a simple vista resultan útiles, debido a que el agente que necesita liquidez puede lograr convertir sus activos en líquidos en un plazo menor, por consiguiente, obtiene efectivo al tiempo presente, mejorando su balance para el cumplimiento de sus objetivos o finalidades.

El proceso se desarrolla en el segmento bursátil del mercado de valores, y surge como consecuencia de la búsqueda de nuevas alternativas de financiamiento a menor costo. Mario O Kenny (2007) establece que la titularización es una fuente de financiamiento fuera de balance, ya que el agente para financiarse utiliza activos, los cuales se transfieren a un patrimonio ajeno, es decir no se registra pasivo. Esta idea la fundamenta Jaime Arrubla al establecer que mediante este mecanismo se obtiene recursos frescos sin necesidad de endeudarse como consecuencia de la reducción del activo sin incrementar el pasivo (Contratos Mercantiles, 2016).

En definitiva, la titularización trae consigo expectativas de gran potencial, ya que a través de esta, se obtienen recursos del mercado de valores a menor costo, y aumenta la liquidez de los agentes al convertir activos inmovilizados en valores negociables. Además a través de este proceso se reactiva las ofertas en el mercado de valores en su segmento bursátil, y se convierte en una gran competencia para el sistema financiero.

De conformidad con el artículo 139 de la Ley de Mercado, los sujetos que intervienen en una titularización son: (i) el originador, (ii) Agente de manejo, (iii) patrimonio de propósito exclusivo, (iv) inversionistas, y (v) comité de vigilancia. 
El originador también conocido como constituyente puede ser una o más personas naturales o jurídicas, de Derecho público o privado, nacional o extranjera, que poseen activos o derechos de los cuales se espera recibir ingresos, susceptibles de titularización (Escobar Gallo \& Cuartas Mejías , 2006).

El agente de manejo es una sociedad que se dedica a la administración de fondos y fideicomisos, y se encuentra autorizada para ejecutar el proceso de la titularización (Contratos Mercantiles, 2016); sus funciones de conformidad con el artículo 139, son: 1) recibir los activos o derechos susceptibles de ser titularizados, 2) crear el patrimonio de propósito exclusivo; 3) emitir valores, 4) colocar los valores en oferta pública; 5) realizar operaciones administrativas que coadyuven a la obtención de flujos futuros .

El patrimonio de propósito de uso exclusivo, es un patrimonio autónomo, separado del patrimonio del originador y del agente de manejo, el cual se compone por los activos que transfiere el originador, y tiene como finalidad respaldar la emisión de valores (Farina, 2014, pág. 32). Finalmente, Los inversionistas se caracterizan por ser personas naturales o jurídicas que suscriben valores mediante la aceptación de una oferta como resultado de un proceso de titularización (Yzquierdo Tolsada, Gómez de Zayas, Ibañéz Jiménez, \& Borgia Sorrosal, 2014).

Es necesario agregar que la doctrina colombiana adiciona como sujetos de la titularización aparte de los mencionados, a la administradora, la colocadora, el estructurador y la calificadora de riesgo (Blanco Barón, 2015). En la legislación ecuatoriana el estructurador y la calificadora de riesgo a pesar de no formar parte de los sujetos de la titularización, intervienen de manera directa en el proceso.

Así, la administradora se encarga de custodiar los activos objetos de la titularización, recaudar y transferir los fondos provenientes al agente de manejo (Jaramillo Betancourt, 2010). Mientras que la colocadora colabora con el emisor, para lograr que los valores objeto de la titularización sean distribuidos en el mercado bursátil, tal gestión es conocida como "Underwriting" (Jaramillo Betancourt, 2010).

Bajo criterio de Sergio Rodríguez el proceso de titularización no es fácil, ya que toda emisión de deuda conlleva a un análisis financiero de manera particular sobre el mercado y sus expectativas en relación con la emisión; de esta manera será el estructurador previo a la ti- 
tularización, quien analizará las necesidades de la entidad y sus alternativas, de ser el caso recomendará la titularización y definirá las características de la emisión (Negocios Fiduciarios , 2017).

Para que exista un mercado informado, se ha acudido a las calificadoras de riesgos, son entidades especializadas en evaluar las emisiones de valores, asignando una calificación, la cual no es exacta sino referencial, previo a la colocación y adquisición por parte de los inversionistas, sobre la oportunidad o capacidad de pago por parte del emisor.

De la definición aportada se debe destacar que la calificación no es para quien emite los valores, ni mucho menos para el originador, debido a que el objeto de la calificación es únicamente la emisión de los valores en relación con sus características, una de ellas son los activos que integran el patrimonio autónomo y que respaldan el proceso de la titularización, y el vehículo a utilizar para instrumentar el proceso de la titularización, que generan confianza.

Luego de haber definido a los participantes del proceso de titularización, es necesario destacar que en calidad de originador puede intervenir un Gobierno Autónomo Descentralizado que se encuentran en búsqueda de recursos para el desarrollo de proyectos o prestación de servicios públicos, para lo cual deberá emitir valores, los mismos que deben estar respaldados por patrimonio autónomo constituido con bienes o derechos susceptibles de titularización. Según el artículo 143 de la Ley de Mercado de Valores, se puede titularizar: (a) Bienes o derechos existentes generadores de flujos futuros determinables, y (b) Derechos de cobro sobre ventas futuras esperadas, esperando que los mismos generen flujos futuros determinables.

El vehículo jurídico que se debe utilizar para estructurar la titularización, de conformidad con el artículo 140 de la Ley de Mercado de Valores, es el fideicomiso Mercantil, debido a que ofrece varias ventajas, entre ellos: (1) gestión de intereses ajenos; y (2) la creación de un patrimonio autónomo (Contratos Mercantiles, 2016), este último de conformidad con el artículo 141, no se encuentra sujetos a gravámenes ni medidas preventivas por parte de los acreedores del originador o de los acreedores. Sin embargo, en relación con los acreedores de los inversionistas, los mismos podrán perseguir los derechos o beneficios que surjan de los valores que adquirió. 
Es claro que, por medio de la titularización se negocian valores, los cuales de conformidad con el artículo 147 de la Ley de Mercado de Valores, son de tres tipos: de contenido crediticio, de participación y mixto. El valor de contenido crediticio es un derecho a favor de los inversionistas de percibir por parte del emisor la cancelación del capital e intereses; el valor de participación certifica que el inversionista adquiere un derecho o porción del patrimonio de propósito exclusivo, con participación en los resultados de utilidad o pérdidas que genere; finalmente, los valores mixtos son una combinación entre valores de participación y de contenido crediticio. (Guía Temática Financiera, 2007, pág. 221).

De conformidad con el artículo 148 de la Ley de Mercado de Valores, los valores se representan mediante títulos o anotaciones en cuenta. Debido a la naturaleza y cuando consten en un soporte cartular los valores surgen de la titularización, serán nominativos o a la orden. Son valores nominativos cuando se expiden a favor de una persona determinada, y para su transmisión se necesita de anotaciones en los libros del emisor, y serán valores a la orden, cuando el cambio de la persona titular se realiza mediante una declaración unilateral por el último tenedor, tal declaración es conocida como endoso (Rodríguez Moreno, 2006).

En la legislación ecuatoriana existen varios tipos de titularización, entre ellas, la titularización de flujos futuros, que de conformidad con el artículo 159 de la Ley de Mercado de Valores, consiste en la emisión de valores con cargo a un patrimonio autónomo, constituido por derechos existentes que son de propiedad del originador, mediante los cuales se prevén generar flujos a futuro. Para entender la aplicación y proceso de este tipo de titularización con la participación de los gobiernos autónomos descentralizados en calidad de originador, se considerará la segunda titularización que realizó el Gobierno Autónomo Descentralizado Municipal del cantón Guayaquil en el año 2015, en aplicación con la normativa que hace posible su instrumentación.

\section{PROCEDIMIENTO DE LA TITULARIZACIÓN EN LOS GO- BIERNOS AUTÓNOMOS DESCENTRALIZADOS}

A partir del caso y de la normativa que regula la titularización en la legislación ecuatoriana, se explicará el procedimiento aplicable para la titularización en los Gobiernos Autónomos Descentralizados como fuente de financiamiento. 
La casuística nos determina que el originador de la titularización es el Gobierno Autónomo Descentralizado Municipal de Guayaquil, el cual de conformidad con el artículo 55, literal c del COOTAD, tiene como competencia exclusiva la planificación, construcción y mantenimiento de la vialidad urbana. Para el cumplimiento de esta competencia el Municipio creó el Programa Integral de Obra Viales de Zonas Densamente Pobladas de la ciudad de Guayaquil Fase III, el cual incluyó la pavimentación de calles con hormigón asfaltico en sectores populares.

Para ejecutar esta última, necesitó de fuentes alternativas de ingresos, escogiendo entre sus opciones la participación en un proceso de titularización, sujetando la misma a la categoría de titularización de derechos existentes generadores de flujos futuros, por un monto de veinte millones; proceso la cual se encuentra respalda por la Ley de Mercado de Valores, el Código Orgánico de Organización Territorial y el Código Orgánico de Finanzas Públicas.

El Municipio determinó la titularización de flujos futuros como fuente de financiamiento, observando los siguientes pasos:

1. Resolución del órgano administrativo que autorice la titularización, es decir el Consejo del Gobierno Autónomo Descentralizado debe aprobar y autorizar. Al respecto, el Municipio de Guayaquil, mediante acta de sesión ordinaria del Consejo Municipal, de fecha 27 de marzo del año 2014 autorizó "La titularización de flujos futuros para financiar obras públicas de pavimentación de sectores populares".

2. El Gobierno Autónomo Descentralizado bajo la Ley Orgánica del Sistema Nacional de Contratación Pública, debe contratar a un estructurador legal y financiero para el proceso de la titularización. El Municipio de Guayaquil, contrató como estructurador legal a Profilegal Ltda., encargándole los siguientes objetivos:

a) Constitución del fideicomiso mercantil irrevocable, en calidad de vehículo del proceso de titularización, mediante escritura pública;

b) Elaboración del prospecto de oferta pública para su aprobación por la Superintendencia de Compañías Valores y Seguros;

c) Declaración juramentada de que los activos se encuentran libres de gravamen; 
d) Gestión legal para obtener la autorización y aprobación por parte del Comité de Deuda Pública y Financiamiento del Ministerio de Finanzas;

e) Obtener aprobación de la oferta pública por parte de la Superintendencia de Compañías, Valores y Seguros;

f) Inscripción de la titularización en la bolsa de valores de Guayaquil;

g) Inscripción de la titularización en el catastro público de valores;

h) Solicitar a la Contraloría General del Estado que realice la correspondiente auditoría financiera.

Además, el estructurador financiero contratado fue Citadel Casa de Valores S.A., se encargó de establecer la estructura de los valores, mismos que fueron de contenido crediticio, recomendó el monto a emitir, el cual fue por veinte millones, colocó los valores en la bolsa para la respectiva adquisición por parte de los inversionistas, valores que fueron colocados en su totalidad, recaudándose los veinte millones que sirvieron para la ejecución de obras públicas de pavimentación de sectores populares.

3. Suscripción del contrato de fideicomiso mercantil de titularización, el cual se otorga mediante escritura pública, creando el patrimonio autónomo y por consiguiente la transferencia de los activos por parte del Gobierno Autónomo Descentralizado. El Municipio de Guayaquil y la administradora de fondos de inversión y fideicomisos Futura Futurfid S.A. en cumplimiento al procedimiento, mediante escritura pública de fecha 24 de noviembre del 2015, en calidad de constituyentes suscribieron el fideicomiso mercantil irrevocable denominado "Segunda Titularización -cems - Municipalidad de Guayaquil”, patrimonio autónomo al cual se transfirió el derecho de cobro que consistía en percibir el cuarenta por ciento de los flujos generados por el pago de las contribuciones especiales por parte de los contribuyentes. El derecho titularizado existente es generador de flujos futuros, es decir es previsible que a futuro se va obtener liquidez como consecuencia de la ejecución del mismo.

El objeto del fideicomiso para el proceso de titularización tuvo como finalidad, entregar al originador los recursos que fueren pagados por los inversionistas por la adquisición de valores, para que este, 
con tales recursos logrará una fuente de financiamiento para la pavimentación de calles con hormigón asfáltico en sectores populares de la ciudad de Guayaquil.

4. Contratación de una compañía calificadora de riesgo con la finalidad que fije una calificación a la titularización. Al ser así, Class International Rating S.A., la encargada de calificar la Segunda Titularización del Municipio, otorgó mediante sesión de fecha 30 de noviembre del 2015 la calificación AAA, como resultado que el patrimonio autónomo contaba con capacidad de generar los flujos esperados y dar cumplimiento con sus obligaciones establecidas en los contratos de emisión.

5. Elaboración del prospecto de oferta pública, este es un comunicado que contiene información suficiente sobre los términos de la oferta y descripción de los valores que se ofrecen en el mercado, el cual deberá ser aprobado por la Superintendencia de Compañías, Valores y Seguros.

6. Solicitud de aprobación del Ministerio de Finanzas, en aplicación con el artículo 142 del Código Orgánico de Planificación y Finanzas Públicas, que establece que "Las emisiones de títulos valores incluidas las titularizaciones de otras entidades públicas, financieras y no financieras, requerirán de la aprobación del ente rector de las finanzas públicas"; mediante resolución ministerial No. 0189 de fecha 22 de septiembre del 2015 el GAD obtuvo la autorización de la segunda titularización.

7. Solicitud de autorización de emisión de valores producto del proceso de titularización a la Superintendencia de Compañías, de conformidad con el artículo 1 de la Codificación de Resoluciones Monetarias, Financieras de Valores y Seguros, Capítulo V, para lo cual se deberá otorgar: prospecto de oferta pública, escritura pública en el que consta el vehículo que será utilizado para la titularización y reglamento de gestión. Además, al tratarse de una titularización de flujos futuros, se necesitará la declaración juramentada donde conste que los bienes que integran el patrimonio autónomo se encuentran libres de gravámenes y estudios técnicos económicos donde se materialice la viabilidad de generar los flujos proyectados.

Constatada la información mencionada, la superintendencia dispondrá la inscripción en el catastro público del Mercado de Valores del emisor y de los valores que se van a emitir; aprobar el proceso de titulari- 
zación y finalmente autorizar la oferta pública debido a la aprobación del contenido del prospecto público. Así, el GAD obtuvo la aprobación de la titularización por la Superintendencia mediante resolución No. SCVS. INMV. DNAR.15. de fecha 29 de diciembre del 2015.

8. Finalmente, inscrita la titularización en la Bolsa de Valores, se da la colocación de los valores objeto de la titularización en el mercado bursátil, mediante el intermediario de valores, en el caso específico fue CITADEL CASA DE VALORES S.A., quién inició la colocación de los valores el 16 de marzo de 2016 y hasta el 01 de febrero del 2017 logró vender en su totalidad los valores, consiguiendo la finalidad de la titularización, es decir financiar la pavimentación de calles con hormigón asfáltico en sectores populares.

Es necesario enfatizar que la contratación de las casas de valores, calificadores de riesgos y administradoras de fondos y fideicomisos, de conformidad con la Codificación de Resoluciones Monetarias, Financieras, de Valores y Seguros, Título III, Sección II, artículo 4, estará a cargo del comité de contratación de cada entidad del sector público y tener a cargo la convocatoria, calificación y selección. La convocatoria para la calificación y selección será publicada en la página web institucional de la Superintendencia de Compañías y Valores y seguros, con la finalidad que los interesados puedan participar, lo cual demuestra mayor transparencia al momento de efectuar la adjudicación del contrato para la prestación de los servicios.

De lo mencionado, se puede destacar que el Gobierno Autónomo Descentralizado para participar como originador de un proceso de titularización de flujo futuros, deberá ser propietario de un derecho que genere flujos, el cual se transfiere a un patrimonio autónomo, y a cargo de esta se podrán emitir los valores, al formar parte del sector público es necesario obtener la autorización del Ministerio de Finanzas para proceder con el proceso de titularización, otro factor importante es la forma de contratación de los actores, tanto como del agente de manejo, casa de valores y de la calificadora de riesgo, pese a ser un proceso que da la oportunidad alternativa de financiamiento a menor costo, se debe considerar que al tratarse del sector público, el trámite se ejecuta con una serie de reglas que deben cumplirse, para precautelar los intereses de la entidad pública y sus activos, porque al final la titularización se encuentra respaldada por un activo estatal, en el caso específico liquidez que proviene de las contribuciones especiales del estado. 


\section{CONCLUSIONES}

Luego de haber realizado un análisis exhaustivo de doctrina y legislación ecuatoriana sobre la titularización de flujos futuros como financiamiento de los Gobiernos Autónomos Descentralizados, se puede denotar que esta herramienta de financiamiento trae consigo ventajas para los GADs, entre ellas la obtención de liquidez a bajo costo, mejorando el balance para el cumplimiento de las competencias exclusivas, lo cual quedó demostrado con el caso que se explicó en el acápite anterior; convirtiéndose los GADs en entidades públicas eficientes en relación con la prestación de servicios y obras públicas, y de esta manera satisfaciendo las necesidades de los ciudadanos.

Además, se observa que la titularización el cual se desarrolla en el Mercado de Valores en su segmento bursátil, se convierte en competencia de las demás alternativas que tienen los GADs para financiarse, entre ellas, el endeudamiento público, debido a que los títulos valores que se emiten en un proceso de titularización se encuentran respaldados por bienes o derechos susceptibles de generar flujos futuros, siendo probable el retorno de la inversión hacia los inversionistas. Además, estos últimos cuentan con información pública que los lleva a tomar una decisión a base de una calificación realizada por una calificadora de riesgos.

Finalmente, cuando se da la participación de un Gobierno Autónomo Descentralizado en calidad de originador se observa que existen reglas que se diferencian de la regla común, entre ellas, la autorización del ente rector de finanzas, así mismo la participación de las entidades que forman parte del proceso de titularización, son elegidas a través de un concurso público, lo que conlleva a denotar que existe mayor control y transparencia, por consiguiente, el proceso de titularización se desarrolla con total eficiencia.

De esta manera se recomienda, que se fomente mediante resoluciones emitidas por la Junta de Política, Regulación Monetaria y Financiera, la participación de los Gobiernos Autónomos Descentralizados en el mercado de valores en calidad de originadores de procesos de titularización, siempre que los GADs requieran de financiamiento para el cumplimiento de sus competencias. A su vez, se debe considerar que, al fomentar este tipo de participación, el uso del mercado bursátil por parte del sector público acrecentaría, ya que en la actualidad es utilizado en su mayoría por el sector privado. 


\section{REFERENCIAS BIBLIOGRÁFICAS}

Andrade Ubidia, S. (2006). Los Títulos Valores en el Derecho Ecuatoriano. Quito: Fondo Editorial.

Andrade, V. R. (2003). Legislación Económica del Ecuador. Quito: Producciones Digitales Abya-Yala.

Arrubla Paucar, J. A. (2016). Contratos Mercantiles. Bogotá: Legis Editores S.A.

Ayala Brito, G. y Becerril Sánchez, B. (2011). Finanzas Bursátiles. México D.F.: Instituto Mexicano de Contadores Públicos.

Baena de Alcázar, M. (2005). Manual de Ciencia de la Administración. Madrid: SÍNTESIS.

Baena Toro, D., Humberto Ramírez, J. y Hoyos Walteros, H. (2007). Guía Temática Financiera. Bógota : Ecoe Ediciones.

Blanco Barón, C. (2015). La Titularización en Colombia: veinte años de regulación 1993,2013. Revista de Economía Institucional,, 259-264.

Buendía, F. (2011). Los Gobiertonos Autónomos Descentralizados. Quito: La Tendencia .

Burneo, R. E. (2013). Derecho Constitucional del Ecuador. Quito: Corporación de Estudios y Publicaciones.

Cayetano Núñez Rivero, J. M. y García Aranda, S. (2013). La Autonomía de los Entes Locales. Madrid: Revista Teoría y Realidad Constitucional.

Cevallos Vásquez, V. (2013). Manual de Derecho Mercantil. Quito: Editorial Jurídica del Ecuador.

Cidoncha Martín, A. (2009). Derecho a la Regulación Económica. Madrid: IUSTEL.

Dromi, R. (2015). Derecho Administrativo. Buenos Aires: Hispana Libros.

Escobar Gallo, H. y Cuartas Mejías , V. (2006). Diccionario Económico Financiero. Medellín: Universidad de Medellín. 
Farina, J. M. (2014). Contratos Comerciales Modernos. Buenos Aires: Editorial Astrea.

Gordillo, A. (2013). Tratado de Derecho Administrativo. Buenos Aires: Fundación de Derecho Administrativo.

Ivanegra, M. M. (2005). Principios de la Administración Pública. Buenos Aires : De Palma.

Jaramillo Betancourt, F. (2010). Valoración de Empresas. Bogotá: Ecoe Ediciones.

Kenny, M. O. (2007). Titulización y Fideicomiso Financiero. Buenos Aires: Errepar.

Lovato Saltos, J. I. (2013). Propuesta de Reformas al Mercado de Valores Ecuatoriano. Quito: Iuris Dictio. Revista del Colegio de Jurisprudencia.

Martínez Damea, A. (2013). La Necesaria Innovación en la Administración Pública. Coruña: Netbiblo.

Martinez Sanz, F. (2014). Manual de Derecho Mercantil. Madrid: Tecnos.

Muñoz Machado, S. (2010). Derecho de la Regulación Económica. Madrid: Iustel.

Peire, J. M. (2012). El Contrato de Fideicomiso Financiero. Buenos Aires: Dunken.

Ramirez Solano, E. (2001). Moneda, Banca y Mercado Financieros. México: Pearson Eduación de México S.A.

Rodriguez Azuero, S. (2017). Negocios Fiduciarios. Bogotá: Legis Editores S.A.

Rodríguez Moreno, H. (2006). Apuntes Básicos en Materia de Títulos Valores. Medillin: Revista Facultad de Derecho y Ciencias Políticas.

Solbes Mira, P. (2007). La Titulización de Activos en Iberoamérica. Madrid: Instituto Iberoaméricano del Mercado de Valores . 
Temiño Aguirre, I. (2007). El Mercado Hipotecario en Latinoamérica. Madrid: Esic Editorial.

Valencia Copete, C. y Garcés, L. R. (2008). Derecho de los títulos valores. Bogotá: Universidad Externado de Colombia.

Vallina Velarde, J. L. (1961). La Desconcentración Administrativa. Oveido: Revista de Administración Pública.

Varón Palomino, J. C. y Abella Abondano, G. D. (2017). Régimen del Mercado de Valores. Bogotá: Editorial Temis S.A.

Villavicencio, G. (2004). La Descentralización y la Situación de los Gobiernos Seccionales. Quito: Tramasocial.

Yzquierdo Tolsada, M., Gómez de Zayas, B., Ibañéz Jiménez, J. W. y Borgia Sorrosal, S. (2014). El Contrato de Suscripción de Valores negociables. En R. Bercovitz Álvarez, S. Borgia Sorrosal, O. Carreras Manero , L. M. De Dios Martínez, S. De Miguel Arias, J. I. Fernández Aguado, ... M. Yzquierdo Tolsada. Contratos Civiles, Mercantiles, Públicos, Laborales e Internacionales, con sus Complicaciones Tributarias (pág. 54). Pamplona: Aranzadi SA.

Zavala Egas, J. (2011). Lecciones de Derecho Administrativo. Guayaquil: Edilex.

\section{Base Legal}

Asamblea Constituyente (2008). Constitución de la República del Ecuador. Montecristi: Registro Oficial 449.

Asamblea Nacional (2010). Código Orgánico de Organización Territorial . Quito: Registro Oficial 303.

H. Congreso Nacional (2006). Código Orgánico Monetario y Financiero, Libro II Ley Mercado Valores. Quito: Registro Oficial 215. 
Recibido: 10 de septiembre de 2018

Aceptado: 26 de noviembre de 2018

Francisco Xavier Jácome Marín, Mgtr.: Docente titular UEES

Correo electrónico: fjacome@uees.edu.ec

Ab. Tanya Mishell Guillen Triana.: Abogada de los Tribunales y Juzgados de la República del Ecuador

Correo electrónico: rfj.derecho.puce@gmail.com 